\title{
Top 10 drugs
}

These tables show the top 10 subsidised drugs in 2005-06. The tables do not include private prescriptions.

\section{Table 1}

Top 10 drugs supplied by DDD*/1000 pop/day ${ }^{\dagger}$

\begin{tabular}{lc}
\hline Drug & PBS/RPBS ${ }^{\ddagger}$ \\
\hline 1. atorvastatin & 116.088 \\
2. simvastatin & 58.702 \\
3. ramipril & 35.897 \\
4. diltiazem hydrochloride & 26.970 \\
5. omeprazole & 19.531 \\
6. frusemide & 18.420 \\
7. salbutamol & 18.073 \\
8. aspirin & 18.047 \\
9. sertraline & 18.039 \\
10. irbesartan & 17.971 \\
\hline
\end{tabular}

\section{Table 2}

Top 10 drugs by prescription counts ${ }^{\dagger}$

\begin{tabular}{ll}
\hline Drug & PBS/RPBS ${ }^{\ddagger}$ \\
\hline 1. atorvastatin & 9045273 \\
2. simvastatin & 6355305 \\
3. paracetamol & 4205023 \\
4. omeprazole & 4180429 \\
5. esomeprazole & 3715500 \\
6. atenolol & 3259401 \\
7. perindopril & 3124409 \\
8. irbesartan & 3025037 \\
9. ramipril & 3024099 \\
10. irbesartan with hydrochlorothiazide & 2962120 \\
\hline
\end{tabular}

\section{Table 3}

Top 10 drugs by cost to Government ${ }^{\dagger}$

\begin{tabular}{lccr}
\hline Drug & $\begin{array}{c}\text { Cost to Government } \\
\text { (\$A) }\end{array}$ & $\begin{array}{c}\text { DDD*/1000/day } \\
\text { PBS/RPBS }{ }^{\ddagger}\end{array}$ & $\begin{array}{c}\text { Prescriptions } \\
\text { PBS/RPBS }\end{array}$ \\
\hline 1. atorvastatin & 522357695 & 116.088 & 9045273 \\
2. simvastatin & 330247669 & 58.702 & 6355305 \\
3. esomeprazole & 169953743 & 14.265 & 3715500 \\
4. clopidogrel & 169947052 & 8.485 & 2179960 \\
5. salmeterol and fluticasone & 165917558 & -5 & 2839015 \\
6. olanzapine & 154623092 & 3.016 & 745603 \\
7. omeprazole & 149094755 & 19.531 & 4180429 \\
8. alendronic acid & 113917837 & 9.177 & 2297414 \\
9. pantoprazole & 103564509 & 11.603 & 2733589 \\
10. pravastatin & 102445719 & 13.934 & 2018695
\end{tabular}

* The defined daily dose (DDD)/thousand population/day is a more useful measure of drug utilisation than prescription counts. It shows how many people, in every thousand Australians, are taking the standard dose of a drug every day.

$\dagger$ Based on date of supply

₹ PBS Pharmaceutical Benefits Scheme, RPBS Repatriation Pharmaceutical Benefits Scheme

$\S$ Combination drugs do not have a DDD allocated

Source: Drug Utilisation Sub-Committee (DUSC) Drug Utilisation Database, as at 9 October 2006. (c) Commonwealth of Australia.

\section{New drugs}

Some of the views expressed in the following notes on newly approved products should be regarded as tentative, as there may have been little experience in Australia of their safety or efficacy. However, the Editorial Executive Committee believes that comments made in good faith at an early stage may still be of value. As a result of fuller experience, initial comments may need to be modified. The Committee is prepared to do this. Before new drugs are prescribed, the Committee believes it is important that full information is obtained either from the manufacturer's approved product information, a drug information centre or some other appropriate source.

\section{Alemtuzumab}

MabCampath (Schering)

glass vials containing $30 \mathrm{mg} / \mathrm{mL}$

Approved indication: chronic lymphocytic leukaemia

Australian Medicines Handbook section 14.3.4
The treatment of chronic lymphocytic leukaemia is changing with increasing use of multidrug regimens including fludarabine (see 'Treatment of adult leukaemias', Aust Prescr 2006;29:76-9). Although response rates have improved, some patients do not respond and in others the disease progresses within a few months. The median survival for these patients with refractory 
disease is only eight months.

Alemtuzumab is a humanised monoclonal antibody that has been studied in chronic lymphocytic leukaemia because it binds to a glycoprotein (CD52) on the surface of lymphocytes. By binding to this antigen alemtuzumab induces lysis of the cell.

In a phase II study, 29 patients with relapsed or refractory disease were given intravenous infusions of alemtuzumab three times a week for up to 12 weeks. Although adverse reactions were common, 11 patients had a partial response and one had a complete response to alemtuzumab. ${ }^{1}$

Another phase II study enrolled 24 patients who had previously been treated with fludarabine. There were no complete responses, but eight patients had a partial response. Overall, median survival was approximately 28 months, but in the responders it was 36 months. $^{2}$

A larger study included 93 patients in whom previous treatment including fludarabine had failed. The aim was to give patients infusions of alemtuzumab three times a week for up to 12 weeks. This regimen resulted in two patients having a complete response and 29 having a partial response. Overall median survival was 16 months. Approximately $10 \%$ of the patients died during the study or within 30 days of treatment. ${ }^{3}$

The infusions of alemtuzumab are given over two hours. The pharmacokinetics of alemtuzumab are not linear as clearance declines during treatment. At the start of treatment the mean half-life is eight hours, but increases to six days.

The dose of the infusion has to be increased gradually as alemtuzumab may be poorly tolerated. Infusion-related reactions include fever, hypotension and gastrointestinal upsets. Nearly $90 \%$ of patients have rigors. There have been fatal cardiovascular adverse events. Premedication with steroids, an analgesic and an antihistamine is recommended.

Most patients will develop a cytopenia. ${ }^{3}$ Transfusions of blood or platelets may be needed.

The action of alemtuzumab means that infections are common 4 and can be fatal. They include pneumonia, and viral and fungal infections. Antibiotic prophylaxis may reduce the risk of pneumocystis pneumonia.

Although alemtuzumab has a clinical benefit for some patients ${ }^{3}$, its role will be limited by its toxicity. At present it is only approved for use after at least two other therapies have failed.

X manufacturer did not respond to request for data

\section{References ${ }^{*}+$}

1. Osterborg A, Dyer MJS, Bunjes D, Pangalis GA, Bastion Y, Catovsky $D$, et al. Phase II multicenter study of human CD52 antibody in previously treated chronic lymphocytic leukemia. J Clin Oncol 1997;15:1567-74.

2. Rai KR, Freter CE, Mercier RJ, Cooper MR, Mitchell BS, Stadtmauer EA, et al. Alemtuzumab in previously treated chronic lymphocytic leukemia patients who also had received fludarabine. J Clin Oncol 2002;20:3891-7.
3. Keating MJ, Flinn I, Jain V, Binet JL, Hillman P, Byrd J, et al. Therapeutic role of alemtuzumab (Campath-1H) in patients who have failed fludarabine: results of a large international study. Blood 2002;99:3554-61.

4. Thursky KA, Worth LJ, Seymour JF, Prince HM, Slavin MA. Spectrum of infection, risk and recommendations for prophylaxis and screening among patients with lymphoproliferative disorders treated with alemtuzumab. Br J Haematol 2005;132:3-12.

\section{Rosuvastatin}

Crestor (AstraZeneca)

$5 \mathrm{mg}, 10 \mathrm{mg}, 20 \mathrm{mg}$ and $40 \mathrm{mg}$ tablets

Approved indication: hypercholesterolaemia

Australian Medicines Handbook section 6.6.1

When patients have hypercholesterolaemia that fails to respond to diet and exercise they may require treatment with an HMG-CoA reductase inhibitor. These drugs are widely prescribed and the approval of rosuvastatin adds to the choice of 'statins'.

Rosuvastatin is taken once a day. Although the tablet's bioavailability is only $20 \%$ it does not have to be taken on an empty stomach or at a particular time of day. While most of the dose is excreted unchanged in the faeces approximately $10 \%$ is metabolised in the liver by cytochrome P450 2C9. Rosuvastatin is contraindicated in people with liver disease. Other patients should have liver function tests before and during treatment.

Rosuvastatin has been compared with atorvastatin, pravastatin and simvastatin in an open-label randomised trial involving 2431 patients. After six weeks rosuvastatin had reduced total cholesterol concentrations significantly more than the other drugs had. It also produced larger increases in concentrations of high density lipoprotein (HDL) cholesterol. A $10 \mathrm{mg}$ dose of rosuvastatin will reduce low density lipoprotein (LDL) cholesterol by $46 \%$ compared to $37 \%$ with $10 \mathrm{mg}$ atorvastatin, $35 \%$ with 20 mg simvastatin and $30 \%$ with 40 mg pravastatin. ${ }^{1}$ (The approximate equivalent doses are rosuvastatin $5 \mathrm{mg}$ = atorvastatin $10 \mathrm{mg}$, simvastatin $20 \mathrm{mg}$, pravastatin $40 \mathrm{mg}$ and fluvastatin $80 \mathrm{mg}^{2}{ }^{2}$ )

The effect on LDL cholesterol may assist patients who are having trouble meeting their targets for risk reduction. In a retrospective study of 8251 patients starting statins, patients taking rosuvastatin were more likely to attain the target concentration of LDL cholesterol. However, the differences in HDL concentrations between statins were not significant. ${ }^{3}$

High doses can reduce the volume of atheroma in coronary vessels, but it is not known if this will improve the clinical outcomes. The doses used in this trial were above the usual maximum daily dose of $20 \mathrm{mg} .{ }^{4}$ Higher doses are likely to cause a higher frequency of adverse reactions.

Adverse effects resulted in $3.7 \%$ of patients in trials discontinuing treatment. These adverse effects include nausea, asthenia, diarrhoea and myalgia. There is a risk of 
rhabdomyolysis which may be increased if the patient is also taking drugs such as gemfibrozil. There are also clinically significant interactions with warfarin and cyclosporin. A few patients develop proteinuria or haematuria while taking rosuvastatin. Asian patients could be at greater risk of adverse effects because they tend to have higher plasma concentrations of rosuvastatin than Caucasians.

Dose for dose, rosuvastatin has a greater effect than other statins on cholesterol concentrations, but it should not become the first choice until data about its longer-term safety and effect on cardiovascular outcomes are available. An American drug bulletin has advised its readers not to use rosuvastatin at all. 5,6 Although there has been criticism that the data supporting rosuvastatin is weak, the company is alleged to have spent an estimated US\$1 billion to persuade doctors to prescribe. ${ }^{6,7}$

\begin{tabular}{ll|l}
$\mathbf{T}$ & $\mathbf{T}$ & $\mathbf{T}$ manufacturer provided all requested information
\end{tabular}

\section{References *}

1. Jones PH, Davidson MH, Stein EA, Bays HE, McKenney JM, Miller $E$, et al. Comparison of the efficacy and safety of rosuvastatin versus atorvastatin, simvastatin, and pravastatin across doses (STELLAR trial). Am J Cardiol 2003;93:152-60.

2. Kendrach MG, Kelly-Freeman M. Approximate equivalent rosuvastatin doses for temporary statin interchange programs. Ann Pharmacother 2004;38:1286-92.

3. Bullano MF, Wertz DA, Yang GW, Kamat S, Borok GM, Gandhi S, et al. Effect of rosuvastatin compared with other statins on lipid levels and national cholesterol education program goal attainment for low-density lipoprotein cholesterol in a usual care setting. Pharmacotherapy 2006;26:469-78.

4. Nissen SE, Nicholls SJ, Sipahi I, Libby P, Raichlen JS, Ballantyne CM, et al. Effect of very high-intensity statin therapy on regression of coronary atherosclerosis. JAMA 2006;295:1556-65.

5. Rosuvastatin (Crestor) - a new but more dangerous cholesterol-lowering 'statin' drug. Worst Pills Best Pills 2003;9:73-6.

6. Further reasons why the cholesterol-lowering 'statin' drug rosuvastatin (Crestor) is a DO NOT USE drug. Worst Pills Best Pills 2004;10:17-9.

7. The statin wars: why AstraZeneca must retreat [editorial]. Lancet 2003;362:1341.

\section{Sorafenib tosylate}

Nexavar (Bayer)

$200 \mathrm{mg}$ tablets

Approved indication: renal cell cancer

Australian Medicines Handbook section 14.3.9

Sorafenib (BAY 43-9006) is a tyrosine kinase inhibitor. Its action on multiple receptors reduces tumour proliferation and angiogenesis. In animal studies it reduced the growth of renal cell carcinoma in mice.
A phase II trial of sorafenib included 202 patients with metastatic refractory renal cell cancer. All the patients took $400 \mathrm{mg}$ sorafenib twice daily for 12 weeks. After 12 weeks 73 patients whose tumours had shrunk by at least $25 \%$ continued treatment. A group of 65 patients whose tumours had not shrunk by $25 \%$ were randomised to continue sorafenib or a placebo. (Patients whose tumours had progressed were withdrawn from the study.) Twelve weeks after randomisation 16 of the 32 patients taking sorafenib were progression free, compared with 6 of the 33 patients taking placebo. ${ }^{1}$

A phase III trial randomised 769 patients with advanced renal cell cancer that had progressed despite a previous systemic therapy, such as interferon. The median time from randomisation to disease progression was 167 days for patients taking sorafenib and 84 days for those taking a placebo.

Patients should probably take sorafenib on an empty stomach as food can reduce bioavailability. Sorafenib is metabolised in the liver by glucuronidation and cytochrome P450 3A4, but no dose adjustment is recommended for patients with mild to moderate liver impairment. Sorafenib has not been studied in patients with severe renal impairment, but only $20 \%$ of a dose is excreted in the urine.

Adverse events are common. In the phase II trial many of the patients developed rashes or a hand-foot skin reaction. Most were able to continue treatment. Nausea, diarrhoea and fatigue were also common. Approximately $17 \%$ of the patients in the phase III study developed hypertension while taking sorafenib, so regular monitoring of blood pressure is needed. Myocardial ischaemia was more frequent with sorafenib than with placebo ( $2.9 \%$ vs $0.4 \%)$. Consider discontinuing treatment if myocardial ischaemia develops. Bleeding occurred in $15 \%$ of the patients taken sorafenib and in $8 \%$ of the placebo group. Particular caution is needed if the patient is taking sorafenib and warfarin. Common laboratory abnormalities include lymphopenia, neutropenia, hypophosphataemia and elevated lipase.

Although sorafenib can reduce tumour size, only $2 \%$ of the patients in the phase III trial had an objective response. The drug therefore seems to keep the disease stable. At the time of writing the effect on survival was uncertain. An interim analysis reported that the median survival was 19.3 months with sorafenib and 15.9 months with placebo.

$\mathbf{T} \mathbf{T}$ manufacturer provided some data

\section{Reference ${ }^{* \dagger}$}

1. Ratain MJ, Eisen T, Stadler WM, Flaherty KT, Kaye SB, Rosner GL, et al. Phase II placebo-controlled randomized discontinuation trial of sorafenib in patients with metastatic renal cell carcinoma. J Clin Oncol 2006;24:2505-12. 


\section{Sunitinib malate}

Sutent (Pfizer)

$12.5 \mathrm{mg}, 25 \mathrm{mg}$ and $50 \mathrm{mg}$ capsules

Approved indications: gastrointestinal stromal tumour, renal cell carcinoma

Australian Medicines Handbook section 14.3.9

Tyrosine kinase inhibitors, such as imatinib, interfere with the angiogenesis that is required for tumour growth (see 'Angiogenesis inhibitors in cancer', Aust Prescr 2006;29:9-15). Sunitinib (SU11248) acts on multiple receptor tyrosine kinases, including a tyrosine kinase which is associated with gastrointestinal stromal tumours. Its anti-angiogenic effects may give it a role in vascular tumours such as renal cell carcinoma.

In an open-label phase II trial, 63 patients were treated with sunitinib after their metastatic renal cell carcinoma had progressed despite immunotherapy. The median duration of treatment was nine months. The investigators' assessment of tumour images found that 25 patients had a partial response to treatment. The median time to further progression of the tumours was 8.7 months with a median survival of 16.4 months. ${ }^{1}$

Another open-label phase II study included 106 patients with metastatic clear cell renal cell carcinoma after immunotherapy had failed. They were treated for about seven months. Independent assessments found that 36 patients achieved a partial response. The median duration of response and median survival had not been reached when the data were analysed. After six months $79 \%$ of the patients were still alive. ${ }^{2}$

Gastrointestinal stromal tumours are sarcomas that usually occur in the stomach or small bowel. Before the development of imatinib, surgery was the only effective treatment but was not always possible. A placebo-controlled trial has investigated giving sunitinib after treatment with imatinib fails. Interim analysis showed a partial response in 14 of the 207 patients randomised to take sunitinib and none of the 105 patients in the placebo group. The time to disease progression was 27.3 weeks with sunitinib and 6.4 weeks with placebo. As this difference could contribute to improved survival all the patients in the placebo group were switched to sunitinib.

The recommended regimen for sunitinib is a daily dose of $50 \mathrm{mg}$ for four weeks followed by a two-week break before repeating the cycle. The dose can be taken with or without a meal as food has no effect on bioavailability. Sunitinib and its active metabolite are metabolised by cytochrome P450 3A4. Dose reductions should be considered if the patient is taking an inhibitor of this enzyme. The dose of sunitinib may need to be increased if an enzyme-inducing drug is prescribed. Patients taking sunitinib should not take St John's wort because of this interaction. The half-life of sunitinib is $40-60$ hours with most of the metabolites being excreted in the faeces. There have been no studies of sunitinib in patients with impaired hepatic or renal function.

In the trials, fatigue, diarrhoea, dyspepsia, nausea and vomiting were common adverse events. Discolouration of the skin or hair, and rashes, particularly on the palms and soles, were also frequently reported. Hypertension developed in $25 \%$ of previously untreated patients with renal cancer and $33 \%$ reported bleeding. Reductions in platelets and blood cell counts are very common. Many patients will also develop abnormal biochemical and liver function tests. Sunitinib can prolong the QT interval and cause left ventricular dysfunction. Deep venous thrombosis and pulmonary embolism have also been reported. As sunitinib has been associated with adrenal toxicity in animal studies, patients experiencing stress, such as surgery, should be monitored for adrenal insufficiency. Approximately $4 \%$ of patients develop hypothyroidism.

The evidence shows that sunitinib is likely to be of benefit to some patients with gastrointestinal stromal tumours who have not responded to imatinib or cannot tolerate it. However, these tumours are uncommon so only a limited number of people will benefit.

Advanced renal cell carcinoma has a poor prognosis. Sunitinib may improve this, but the results need to be confirmed in randomised phase III studies. Preliminary data suggest that there may be a greater response to sunitinib than to immunotherapy with interferon alfa. ${ }^{3}$

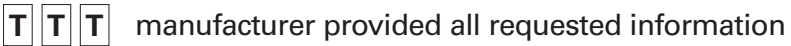

\section{References ${ }^{*} \dagger$}

1. Motzer RJ, Michaelson MD, Redman BG, Hudes GR, Wilding G, Figlin RA, et al. Activity of SU11248, a multitargeted inhibitor of vascular endothelial growth factor receptor and platelet-derived growth factor receptor, in patients with metastatic renal cell carcinoma. J Clin Oncol 2006;24:16-24.

2. Motzer RJ, Rini BI, Bukowski RM, Curti BD, George DJ, Hudes GR, et al. Sunitinib in patients with metastatic renal cell carcinoma. JAMA 2006;295:2516-24.

3. Phase III study of sunitinib malate (SU11248) versus interferon- $\alpha$ as first-line treatment in patients with metastatic renal cell carcinoma. Clin Genitourin Cancer 2006;5:23-5.

\section{Further reading}

Pavlakis N. Drug treatment of renal cancer. Aust Prescr 2006;29:151-3. 
The T-score ( $\mathbf{T}$ ) is explained in 'Two-way transparency', Vol 28 No 4, 2005 (Aust Prescr 2005;28:103).

* At the time the comment was prepared, information about this drug was available on the website of the Food and Drug Administration in the USA (www.fda.gov).

+ At the time the comment was prepared, a scientific discussion about this drug was available on the website of the European Agency for the Evaluation of Medicinal Products (www.emea.europa.eu)

\section{www.australianprescriber.com}

Australian Prescriber is available on the internet in full text, free of charge. Go to New issue email alert to be sent an email each time a new issue goes online.

\section{Australian Prescriber mailing list}

Australian Prescriber is distributed every two months, free of charge, to medical practitioners, dentists and pharmacists in Australia, on request. It is also distributed free of charge, in bulk, to medical, dental and pharmacy students through their training institutions in Australia. To be placed on the mailing list contact the Australian Prescriber Mailing Service.

Tick $\checkmark$ whichever of the following apply:

I have access to the Australian Prescriber website on the internet $\square$ Yes $\square$ No

$\square$ Place me on the mailing list

Delete me from the mailing list

Change my address

Send me all the available back issues

Name:

Ref no.:

(on the address sheet above name)

Address:

Profession:

(general practitioner, resident, psychiatrist, surgeon, dentist, pharmacist etc.)

Postal: $\quad$ Australian Prescriber Mailing Service GPO Box 1909 CANBERRA ACT 2601 AUSTRALIA

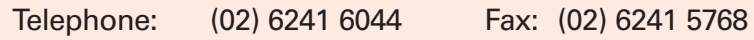

\section{Editorial office}

For general correspondence such as Letters to the Editor, contact the Editor.

Telephone: (02) 62023100

Fax: $\quad$ (02) 62826855

Postal: The Editor Australian Prescriber Suite 3, 2 Phipps Close DEAKIN ACT 2600 AUSTRALIA

Email: info@australianprescriber.com

Website: www.australianprescriber.com
1. False
3. True
5. False
7. True
2. False
4. True
6. False
8. False
9. True
10. False 